\title{
Dysplastic ichtyosis uteri of endometrium associated with squamous cell carcinoma insitu of cervix -does it have malignant potential
}

\author{
Rayapa Reddy Thumma ${ }^{1}$, Ravi Krishana ${ }^{2}$, Premalatha Pidakala ${ }^{3}$ \\ 1, 2, 3, Department of Pathology, \\ NRI Medical College, Dr. NTR University of Health Sciences, India
}

\begin{abstract}
Ichthyosis uterus is an exceedingly rare condition in which the entire surface of the endometrium is replaced by stratified squamous epithelium. Originally described as an endometrial response to iatrogenicallyintroduced caustic substances, similar changes have since been described in association with a variety of inflammatory conditions of the endometrium. We describe here an undescribed example of a carcinoma insitu of the uterine cervix associated with extensive ichthyosis uteri-like changes of the entire endometrium. Additionally, the squamous epithelium of the latter also showed multifocal changes diagnostic of a low-grade squamous intraepithelial lesion. The potential genesis of this composite of findings is discussed, as is the neoplastic potential of ichthyosis uteri.

The possibility of significant cervical pathology should be considered when plaques of squamous epithelium with low grade dysplastic changes are identified in an endometrial biopsy or curettage.

Key words: Ichthyosis uteri, squamous metaplasia, Carcinoma cervix
\end{abstract}

\section{INTRODUCTION:}

A 53 year old multigravida presented with features of vague pelvic heaviness and vaginal discharge and burning micturition since 20 days. Her past medical history was unsignificant with no history of tuberculosis, inflammatory conditions of uterus or iatrogenetically induced substances in uterus. She had attained menopause about 8 years back.

Gynaecological examination revealed raw areas on anterior lips of cervix which was bleeding on touch. Ultrasound abdomen and pelvis revealed retroverted uterus with normal echo texture. No focal lesions. Endometrial cavity shows collections with septations. Ectocervical biopsy showed strips of moderate to severe dysplastic squamous epithelium. The patient underwent abdominal hysterectomy. The procedure was well tolerated and the post operative period was uneventful.

\section{I.1 Pathological findings:}

Gross: Hysterectomy specimen revealed ulceration of the cervix. Cut section showed widened endometrial cavity and the entire endometrium showed multiple grey white tiny nodules. Both tubes and adneaxe are unremarkable (Fig-1).

Microscopy: Sections revealed entire endometrium replaced by stratified squamous epithelium showing areas of keratinization, koilocytic changes, nuclear hyperchromasia with moderate increase in nuclear-cytoplasmic ratio indicating low grade dysplastic changes in underlying ichthyosis uteri (Fig-3 \& 4). Extensive sampling did not reveal normal endometrial glands beneath the dysplastic epithelium. Sections from the cervix showed high grade squamous intra epithelial lesion (Fig-2).

\section{DISCUSSION:}

The presence of squamous epithelium in the endometrium, various termed (Ichthyosis uteri) a condition in which endometrium is replaced by keratinized squamous epithelium, leukoplakia epidermidization, psoriasis uteri, epidermoid heteroplasia, cholesteometra and indirect regenerative squamous metaplasia has been described under a variety of cases and is benign in majority of cases

The term "ichthyosis uteri" was initially coined in 1885 by Zeller to refer to extensive squamous metaplasia of the surface endometrium following iatrogenically-introduced caustic substances such as formalin or iodine. ${ }^{\left[{ }^{1]}\right.}$ Since that initial report, the term "ichthyosis uteri" and the phenomenon it describes have become well accepted but has been used only sporadically in the literature. ${ }^{[2-5]}$ Similar changes have been seen in association with tuberculous endometritis, puerperal endometritis, endometrial polyps, hyperplasia and pyometra secondary to cervical stenosis or malignancies. It may provide the setting for the rare pure squamous carcinoma of the endometrium. ${ }^{[6]}$ 
The case reported herein is a squamous cell carcinoma insitu of cervix associated with extensive ichthyosis like changes of the endometrium that, additionally had superimposed low grade dysplastic changes. This composite of findings may be explained in two, somewhat mutually exclusive ways: The first and most plausible explanation, and which formed the basis of the clinical diagnosis actually rendered, is that a squamous cell carcinoma originated in the cervix and the associated HPV extended proximally, colonizing pre-existing ichthyosis uteri.

The second potential explanation is that a lepidic, surface extension of a cervical squamous cell carcinoma (and no pre-existing ichthyosis uteri), the presence of dysplastic or koilocytic changes in many segments of the endometrial squamous epithelium suggests this possible mechanism.

The case in the literature that most closely resembles our case was reported by Patton and Squires in 1962. ${ }^{[7]}$ The patient described in that report underwent a hysterectomy for severe pyometra. Microscopic evaluation showed extensive high-grade dysplasia of the cervix (with a focal area of micro invasion) and ichthyosis uteri of the endometrium. However, areas of the squamous epithelium in the endometrium also showed some degree of "cellular anaplasia", which the authors interpreted as a direct extension from the cervix. Pins et al described a somewhat similar case in which high-grade dysplasia of the cervix (and without invasion) extended proximally and coated the entire endometrium. ${ }^{[8]}$ Both of these cases differ from the current case in that the dysplasia of the endometrial squamous epithelium in the latter was multifocal and low-grade, which argues against the possibility of a direct lepidic spread of the cervical tumor.

In the experience of some authors ${ }^{[9]}$, ichthyosis uteri lacks any malignant potential, However, the rarity of ichthyosis uteri hinders the interpretation of the significance of anecdotal cases of neoplasms arising from this entity. Presumably, longstanding, mature, plaque-like and even keratinizing squamous epithelium in the endometrium would subject to the same potential changes as squamous epithelium in other visceral sites.

A case of a benign papilloma arising in a background of extensive ichthyosis uteri was reported by Kucukali et al. ${ }^{[4]}$ Similarly, malignancies have rarely been associated with ichthyosis uteri. Squamous cell carcinomas of the endometrium have been observed to arise either directly or in association with ichthyosis uteri. ${ }^{[10]}$ Bewtra et $\mathrm{al}^{[3]}$ recently described a case of endometrial adenocarcinoma covered almost entirely by a plaque-like, keratinizing mature squamous epithelium. The latter is in contrast to the plaque-like squamous differentiation which is rarely seen in endometrioid adenocarcinomas of the endometrium ${ }^{[11]}$; these changes are generally focal or multifocal and are not diffuse as is seen in ichthyosis uteri. Finally, ichthyosis uteri in the clinical course of case of endometrial adenocarcinoma was reported by Sikorowa in 1969. ${ }^{[12]}$ Although the number of cases of ichthyosis uteri associated with malignancies is disproportionately high relative to the overall number of cases reported, this is likely a bias created by the reporting of individual case reports. In our opinion, there is insufficient evidence to suggest that uncomplicated (i.e non-dysplastic) ichthyosis uteri has any intrinsic neoplastic potential.

In summary, a case of squamous cell carcinoma insitu of the cervix with probable proximal extension into, and colonization of pre-existing ichthyosis uteri by associated HPV is described. The possibility of significant cervical pathology should be considered when plaques of squamous epithelium with low grade dysplastic changes are identified in an endometrial biopsy or curettage.

\section{REFFRENCES:}

[1]. Patton WT, Squares GV. Ichthyosis uteri: a case report.Am J Obstet Gynecol. 1962;84:858-860.

[2]. Marcus SL: Adenoacanthoma of the endometrium: a report of 24 cases and a review of squamous metaplasia. Am J Obstet Gynecol 1961, 81:259-267.

[3]. Bewtra C, Xie QM, Hunter WJ, Jurgensen W: Ichthyosis uteri: a case report and review of the literature. Arch Pathol Lab Med 2005, 129:e124-125.

[4]. Kucukali T, Ertoy D, Ayhan A: Ichthyosis uteri associated with a uterine squamous papilloma. Eur J Gynaecol Oncol 1996,17:3741.

[5]. Zschoch H, Ertel G: Ichthyosis uteri-squamous cell epithelial metaplasia of the endometrium. Zentralbl Allg Pathol 1987,133:355360 .

[6]. Hendrickson MR, Kempson RL. Surgical Pathology for the Uterine Corpus.Philadelphia, Pa: WB Saunders; 1980:170-171. Major Problems in Pathology.

[7]. Patton WT, Squires GV: Ichthyosis uteri. A case report. Am J Obstet Gynecol 1962, 84:858-860.

[8]. Pins MR, Young RH, Crum CP, Leach IH, Scully RE: Cervical squamous cell carcinoma in situ with intraepithelial extension to the upper genital tract and invasion of tubes and ovaries: report of a case with human papilloma virus analysis. Int J Gynecol Pathol 1997, 16:272-278.

[9]. Zaino RJ: Metaplasia. In Interpretation of endometrial biopsies and curettings Edited by: Silverberg SG. Philadelphia: LippincottRaven; 1996:241-261.

[10]. Anderson MC, Robboy SJ, Russell P, Morse A: Endometritis, metaplasia, polyps and miscellaneous changes. In Pathology of the female reproductive tract Edited by: Robboy SJ, Anderson MC, Russell P. London: Churchill-Livingstone; 2002:303.

[11]. Clement PB, Young RH: Endometrioid carcinoma of the uterine corpus: a review of its pathology with emphasis on recent advances and problematic aspects. Adv Anat Pathol 2002, 9:145-184.

[12]. Sikorowa L: A case of ichthyosis of the uterus in the course of adenocarcinoma of the corpus uteri. Nowotwory 1969, 19:65-70. 


\section{FIGURES}

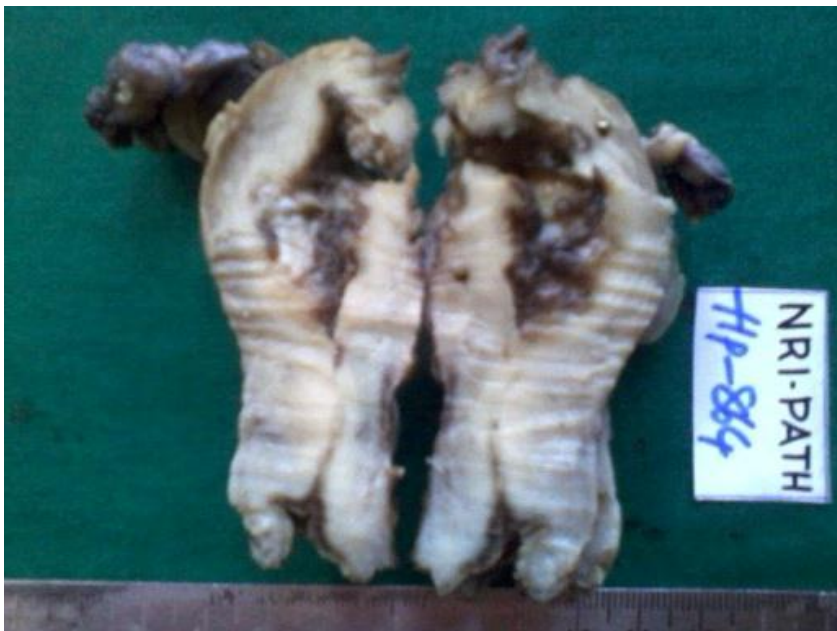

Fig 1: Cut section showing widened endometrial cavity and the surface showing multiple tiny grey white nodules.

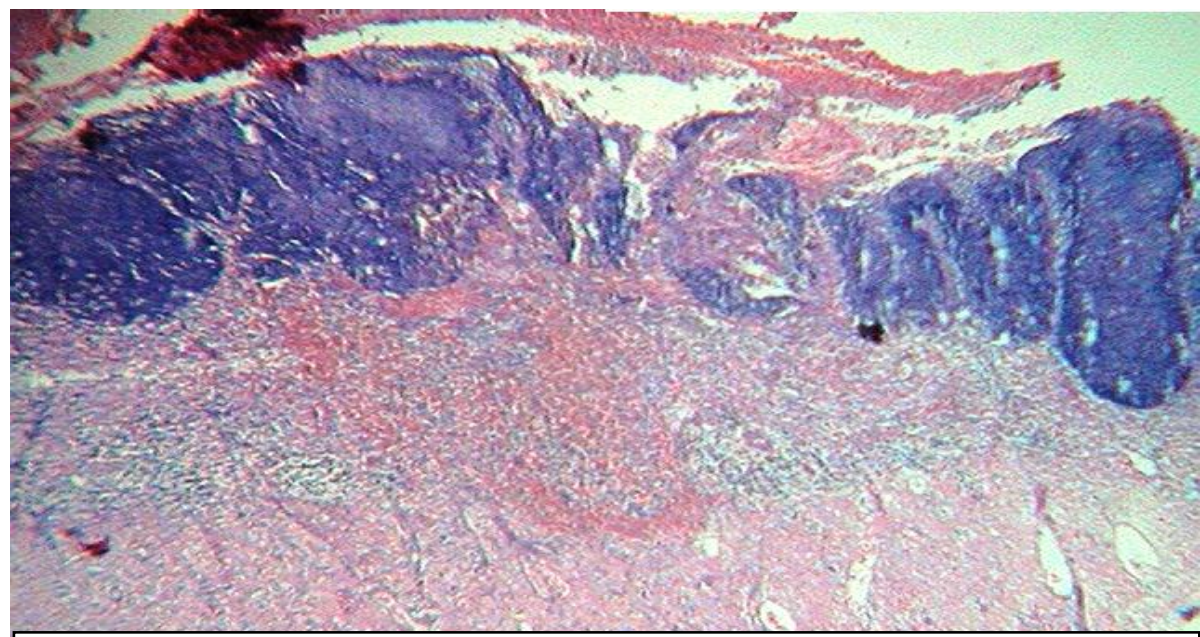

Fig 2: H\&E X100 showing surface ulceration of cervix with CIN III changes

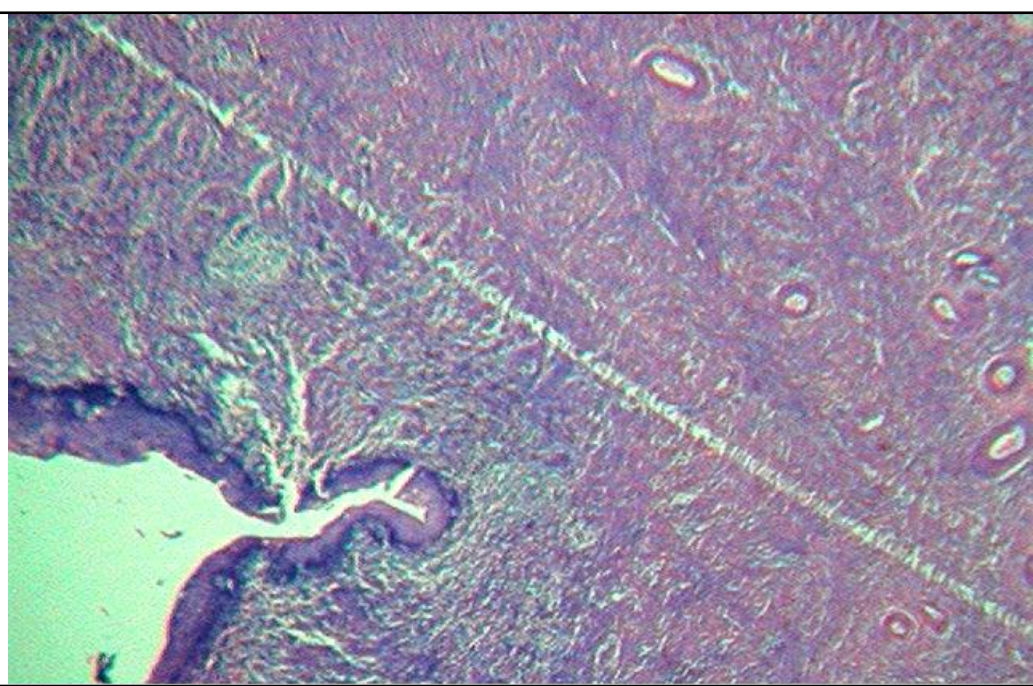

Fig 3: H\&E X100 showing squamous epithelium lining the endometrium with underlying myometrium showing thickened blood vessels 


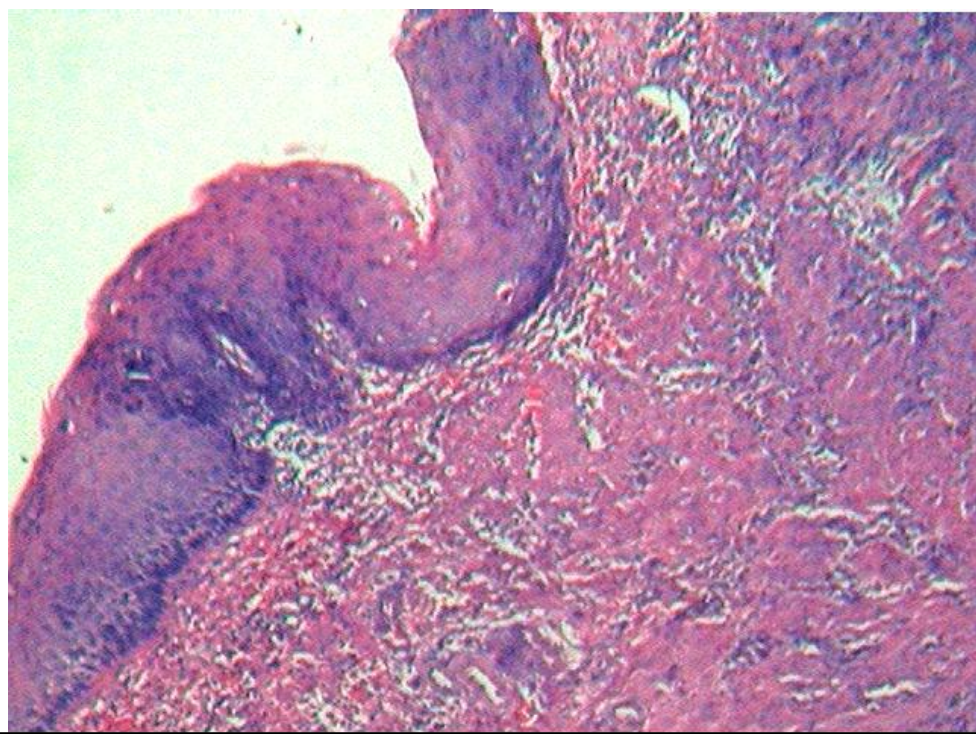

Fig 4: H\&E X400 squamous epithelium lining the endometrium showing mild dysplastic changes 